\title{
Verbal advice plus an information leaflet reduced antibiotic use in patients presenting with acute bronchitis
}

\author{
Macfarlane J, Holmes W, Gard P, et al. Reducing antibiotic use for acute bronchitis in primary care: blinded, randomised \\ controlled trial of patient information leaflet. BMJ 2002 Jan 12;324:91-4.
}

\section{QUESTION: In patients presenting with acute bronchitis, does verbal advice plus an information leaflet describing the uncertain value of antibiotics for this condition reduce antibiotic use more than verbal advice alone?}

\section{Design}

Randomised (unclear allocation concealment), blinded (clinicians and data collectors) controlled trial with 4 weeks of follow up.

\section{Setting}

3 general practices in Nottingham, UK.

\section{Patients}

259 consecutive adults $\geqslant 16$ years of age presenting with acute bronchitis, defined as a new acute lower respiratory tract illness (ie, illness for $\leqslant 21 \mathrm{~d}$; main symptom of cough; $\geqslant 1$ symptom of sputum production, dyspnoea, wheeze, or chest discomfort or pain; and no alternative explanation), who were not under medical supervision for an underlying disease such as asthma, chronic obstructive pulmonary disease, heart disease, or diabetes. 47 patients were judged to need antibiotics immediately. 212 patients were judged to not need antibiotics immediately and were subsequently randomised (median age $44-45$ y, 58\% women). 205 of these patients $(97 \%)$ were included in the analysis.

\section{Intervention}

All patients received a prescription for antibiotics. 106 patients were allocated to verbal advice from the general practitioner plus an information leaflet. Verbal advice was based on a prompt card: "I have examined you and I am happy there is no sign of serious disease which definitely needs antibiotics today. Most chesty illnesses get better on their own, although the cough may take a long time to go completely. Antibiotics don't seem to make much difference to how quickly most people recover. However, if you feel you are getting worse after a while, considering taking antibiotics then would be reasonable. So, here is a prescription for an antibiotic for you to keep at home. You are quite likely not to need it, but use your judgment whether to get them in due course." The information leaflet described the natural course of lower respiratory tract symptoms and the advantages and disadvantages of antibiotic use. 106 patients were allocated to verbal advice alone.

\section{Main outcome measures}

Patient use of prescribed antibiotics (self report) within the next 2 weeks and initiation of further consultation for the same symptoms within the next 4 weeks.

\section{Main results}

Fewer patients who received verbal advice plus the information leaflet took their antibiotics than did patients who received verbal advice alone (table). The groups did not differ for reconsultation rates at 4 weeks $\{11 \%$ v $13 \%, \mathrm{p}=0.54\}$.*

\section{Conclusion}

Verbal advice plus an information leaflet describing the uncertain value of antibiotics reduced antibiotic use more than verbal advice alone in patients presenting with acute bronchitis.

*Calculated from data in article. acute bronchitist

†Abbreviations defined in glossary; RRR and Cls calculated from data in article.

\section{COMMENTARY} ing to the continued use of antibiotics. ${ }^{2}$ additional patient. little assistance in decision making. able affects patient decision making. Rev 2002;(1):CD000245. Med 2002;162:256-64. Fam Pract 2000;13:462-3.
Source of funding: British Lung Foundation.

For correspondence: DrJ Macfarlane, Nottingham City Hospital, Nottingham UK.john.macfarlane@ tinyworld.co.uk

A modified version of this abstract appears in Evidence-Based Medicine.

Physician verbal advice plus an information leaflet $v$ verbal advice alone for patients with

\begin{tabular}{lllll} 
Outcome at 2 weeks & $\begin{array}{l}\text { Verbal advice } \\
\text { plus leaflet }\end{array}$ & $\begin{array}{l}\text { Verbal advice } \\
\text { alone }\end{array}$ & RRR (95\% CI) & NNT (CI) \\
\hline Antibiotic use & $47 \%$ & $62 \%$ & $24 \%(3$ to 42$)$ & 7 (4 to 63$)$ \\
\hline tAbbreviations defined in glossary; RRR and Cls calculated from data in article.
\end{tabular}

Although the ineffectiveness of antibiotics in the treatment of acute bronchitis is well documented, ${ }^{1}$ antibiotic prescribing rates remain high. ${ }^{2}$ Diagnostic uncertainty, patient expectations, and patient satisfaction are factors that have been identified as contribut-

Studies have examined the effects of educating practitioners and patients about antibiotic use. Patient education has the potential to reduce antibiotic use while maintaining patient satisfaction. The study by Macfarlane $e$ al compared the effectiveness of verbal advice alone versus verbal advice plus written patient education. The study was well designed and showed that verbal advice plus written instructions reduced antibiotic use. Based on the number needed to treat (NNT), 7 patients would need to receive verbal advice plus written patient education to reduce unnecessary antibiotic use in 1

MacFarlane et al added the variable of patient autonomy to this study, allowing patients to make the ultimate decision about antibiotic use. Placing this decision in patients' hands could potentially increase or decrease antibiotic use. Empowerment is likely to increase patient satisfaction, and patients who feel empowered may consider their choices more carefully. Alternately, the fact that the prescription was given may suggest to them that antibiotics will likely be required. The only criterion patients were given for taking antibiotics was that the illness or cough was "getting worse", providing

Further study is needed to resolve the prognostic uncertainty of prolonged symptoms and provide clearer guidelines about who ultimately needs antibiotics. ${ }^{3}$ In addition, more study of the influence of patient autonomy would clarify how this vari-

$$
\begin{array}{r}
\text { Stephanie Wright, RN, CFNP, CPNP, PhD } \\
\text { Associate Professor } \\
\text { Georgetown University - School of Nursing and Health Studies } \\
\text { Washington, DC, USA }
\end{array}
$$

1 Smucny J, Fahey T, Becker L, et al. Antibiotics for acute bronchitis. Cochrane Database Syst

2 Hirschmann JV. Antibiotics for common respiratory tract infections in adults. Arch Intern

3 Hickner JM. Antibiotic prescribing for acute bronchitis: how low can we go? J Am Board 